\title{
EFEITO DAS CONDIÇÕES DE EXTRAÇÃO NO RENDIMENTO E QUALIDADE DO LEITE DE CASTANHA-DO-BRASIL DESPELICULADA
}

\author{
ILANA FERBERG * \\ LAIR CHAVES CABRAL * \\ ELISABETH BORGES GONÇALVES * \\ ROSIRES DELIZA *
}

\begin{abstract}
O objetivo deste trabalho foi avaliar os efeitos das condições de extração no rendimento e qualidade do leite de castanhado-Brasil despeliculada. O processo básico para elaboração do referido leite incluiu as etapas de despeliculação das amêndoas das castanhas, desintegração das castanhas despeliculadas e centrifugação do produto. Na etapa de desintegração foram estudadas 4 temperaturas $(25,50,75$ e $100^{\circ} \mathrm{C}$ ) com uma ou duas extrações. As amostras experimentais obtidas foram avaliadas quanto à composição, rendimento em extração e avaliação sensorial de doçura. Os leites de castanha obtidos a $75^{\circ} \mathrm{C}$ com 1 e 2 extrações apresentaram rendimento em sólidos, proteínas e óleo significativamente $(p=0,05)$ superiores aos demais. O leite de castanha elaborado a $75^{\circ} \mathrm{C}$ com uma extração, considerado o melhor sob o ponto de vista tecnológico, foi formulado com diferentes concentrações de açúcar $(2,3$ e $4 \%$ ) e submetido ao teste de preferência. O leite de castanha, com $3 \%$ de açúcar foi preferido por $78 \%$ dos consumidores que avaliaram o produto.
\end{abstract}

PALAVRAS-CHAVE: CASTANHA-DO-BRASIL - EXTRAÇÃO; CASTANHA-DO-BRASILRENDIMENTO.

\section{INTRODUÇÃO}

A castanha-do-Pará, denominada como castanha-do-Brasil para efeito de comércio exterior, é a semente da castanheira Bertholletia excelsea, da família das Lecythidaceae, encontrada numa vasta região da América Latina, principalmente na região Amazônica (SOUZA et al.,1987; REGITANO-d'ÁRCE e SIQUEIRA,1995; BONELLI et al., 2001).

\footnotetext{
* Pesquisadores da Embrapa Agroindústria de Alimentos, Guaratiba, Rio de Janeiro, RJ. (e-mail: ilana@ctaa.embrapa.br).
} 
O consumo da castanha-do-Brasil no país é muito reduzido e estima-se que apenas $1 \%$ da sua produção de, aproximadamente, 20 mil toneladas seja consumida internamente (RIBEIRO et al., 1995; VIEIRA e REGITANOd'ÁRCE, 1999). A maior parte da produção é exportada in natura, principalmente para a Europa e os Estados Unidos, como petisco (delicatessen) (WOODROOF, 1982, RIBEIRO et al., 1995). O valor de exportação da castanha-do-Brasil, dentre os produtos da Amazônia, só é ultrapassado pelo da borracha (BONELLI et al., 2001).

Devido ao agradável sabor e elevado valor nutritivo, a castanha pode ser incorporada à dieta da população brasileira. Para tanto, seria necessário ampliar o seu aproveitamento industrial (REGITANO-d'ÁRCE e SIQUEIRA, 1995; SOUZA et al., 1987) e promover maior divulgação de seu valor nutricional, bastante elevado quando comparado ao de frutas e outras nozes. A castanha-do-Brasil apresenta alto conteúdo lipídico (60-70\%) e protéico (15-20\%), além de elevado teor de metionina (aminoácido essencial deficiente em muitas proteínas de origem vegetal, especialmente nas leguminosas) (WOODROOF, 1982; SUN et al., 1987; ANTUNES e MARKAKIS, 1977). O óleo da castanha-do-Brasil apresenta potencial para uso como óleo fino de mesa e na área de cosméticos (ANTONIASSI et al., 1998). A castanha-do-Brasil é também rica em selênio, importante antioxidante que vem sendo relacionado à redução de risco de câncer de pele. Uma única castanha fornece cerca de $120 \mu \mathrm{g}$ de selênio, quantidade superior às necessidades diárias recomendadas deste mineral (SIGHTINGS, 1998; LEAVANDER, 1983).

A castanha-do-Brasil é muito utilizada, entre os nativos da região Amazônica, na preparação de pratos típicos. O "leite de castanha-doBrasil", por exemplo, é consumido puro, principalmente na alimentação infantil, e em pratos regionais. A farinha é utilizada na preparação de biscoitos, doces, bolos e no enriquecimento de outras farinhas (CASTANHA: produtos..., 1998).

A amêndoa da castanha-do-Brasil pode ser consumida sob várias formas, ou seja, in natura, desidratada, salgada, tostada, coberta com chocolate, caramelo, açúcar, mel ou outras coberturas. Também pode ser utilizada em produtos como granolas, sorvetes, chocolates, bolos, doces e biscoitos, como farinha ou "leite" de castanha.

Alguns estudos têm sido realizados em escala de laboratório para obtenção de leite de castanha-do-Brasil (PEREIRA, 1976; SOUZA et al.,1987; REGITANO-d'ÁRCE e SIQUEIRA, 1995; CARDARELLI et al., 1995; 
CASTANHA: produtos...,1998). O processo básico para sua obtenção envolve as etapas de despeliculação ou não das amêndoas, extração, separação do resíduo insolúvel, formulação, embalagem e tratamento térmico. SOUZA et al. (1987) realizaram despeliculação manual das castanhas com auxílio de facas de aço, utilizando a proporção de 2:1 (água e castanha) na trituração em liquidificador. Filtraram sob pressão manual com tecido de algodão e efetuaram nova homogeneização do extrato resultante em liquidificador para redução do tamanho das partículas. Obtiveram $14,98 \%$ de matéria seca, $0,90 \%$ de proteína, $10,85 \%$ de extrato etéreo e $0,33 \%$ de cinzas. REGITANO-d'ÁRCE e SIQUEIRA (1995) utilizaram prensa hidráulica para obtenção de torta de castanha semidesengordurada que foi desintegrada em água na proporção de 1:2. Tais autores obtiveram $16,30 \%$ de matéria seca, $5,17 \%$ de teor de óleo e $15,54 \%$ de proteína. PEREIRA (1976) estudou a obtenção de extratos solúveis de castanha-do-Brasil, utilizando soluções salinas $(\mathrm{NaCl})$, trituração em liquidificador a 3000 rpm e variação de tempo e temperatura de extração. Encontrou como condições mais favoráveis o tempo de 45 minutos em três extrações sucessivas, a temperatura de $24^{\circ} \mathrm{C}$ em solução salina de $0.25 \mathrm{M}$.

O presente trabalho teve como objetivo verificar, em nível de planta piloto, o efeito das condições de extração no rendimento e na qualidade do leite de castanha-do-Brasil despeliculada, visando à obtenção de produto pronto para o consumo, ingrediente culinário ou para utilização em bebidas formuladas.

\section{MATERIAL E MÉTODOS}

\subsection{MATÉRIA-PRIMA}

Utilizou-se como matéria-prima castanha-do-Brasil (Bertholletia excelsea, H.B.K) in natura, sem casca, com película, procedente de Belém do Pará, safra 2000. As castanhas foram recebidas em único lote de $20 \mathrm{~kg}$, separadas e embaladas a vácuo, em pacotes de cerca de $1,5 \mathrm{~kg}$ e armazenadas em freezer.

\subsection{DESPELICULAÇÃO}

O método utilizado para despeliculação foi o descrito por SANT'ANNA, (1985), com modificações. As castanhas foram imersas em solução de 
hidróxido de sódio 2\%, em ebulição por 1 minuto, na proporção de 2:1 (solução de $\mathrm{NaOH}$ : castanha). Após foram drenadas, colocadas em água fria na proporção de 5:1 (água: castanha) por 2 minutos, despeliculadas manualmente em água corrente, e imersas novamente em água fria por 10 minutos para eliminar o resíduo de hidróxido de sódio. A confirmação da ausência deste resíduo foi realizada mediante verificação com gotas de solução de fenoftaleína numa parte das castanhas.

\subsubsection{Obtenção do leite de castanha e sua avaliação tecnológica}

Para obtenção do leite de castanha com uma extração, as amêndoas despeliculadas foram trituradas com água em liquidificador industrial Warner Blender na proporção de 1:8 (castanha: água) por 3 minutos, empregandose água a temperaturas de $25,50,75$ e $100^{\circ} \mathrm{C}$. A dispersão resultante foi centrifugada por 2 minutos em centrífuga de cesto multiuso, modelo K7165, contendo saco de nylon com furos de 150 microns no interior do cesto.

$\mathrm{Na}$ elaboração do leite de castanhas com duas extrações, a primeira extração foi realizada na proporção de 1:4 (castanha: água) nas mesmas condições anteriores. Após a centrifugação, o extrato foi separado e o resíduo sólido resultante desta primeira extração triturado com água, completando a proporção inicial de 1:8. O extrato resultante desta segunda extração foi adicionado ao extrato resultante da primeira extração, sendo efetuadas três repetições de cada processamento.

A avaliação tecnológica foi realizada considerando-se o teor de sólidos totais, proteínas e lipídios, bem como o rendimento em sólidos.

\subsubsection{Obtenção do leite de castanha para avaliação sensorial}

O leite de castanha selecionado pelos critérios tecnológicos foi formulado a $60{ }^{\circ} \mathrm{C}$ com adição de ingredientes e aditivos, sendo açúcar (2, 3 ou 4\%), sal $(0,1 \%)$, carboxi-metil-celulose (CMC - 0,1\%) e monoestearato de glicerila (MEG - 0,5\%). Após, os leites foram homogeneizados em equipamento APV GAULIN, Modelo MR15, à pressão de 3000 psi e submetidos à avaliação de preferência quanto à doçura.

\subsubsection{Composição centesimal aproximada da matéria-prima e dos leites de castanha-do-Brasil e rendimentos de extração}

As determinações de umidade e cinzas foram realizadas de acordo com 
a AOAC (1984) e proteína bruta e teor de lipídios, segundo a AOCS (1980). Determinou-se o teor de lipídios do leite-de-castanha conforme método de BLIGH e DYER (1959), sendo os carboidratos calculados por diferença. As análises químicas foram realizadas com três repetições. Os rendimentos de extração dos processos em termos de sólidos totais, proteínas e lipídios foram calculados através desses teores nos leites finais obtidos em relação aos existentes na castanha com película.

\subsubsection{Avaliação sensorial}

O leite de castanha elaborado a $75^{\circ} \mathrm{C}$ com uma extração, considerado o de melhor performance tecnológica, foi submetido a teste com consumidor para determinação do teor de açúcar preferido. As quatro formulações de leite de castanha, contendo 0, 2, 3 e 4\% de açúcar, foram avaliadas por oitenta provadores (50 mulheres e 30 homens) com idade variando de 18 a 53 anos. A ordem de apresentação das amostras seguiu delineamento de blocos completos, segundo MacFIE et al. (1989). Foi utilizada escala hedônica de nove pontos variando de "gostei extremamente" a "desgostei extremamente". Observações espontâneas (o que mais gostou e o que mais desgostou do produto) também foram registradas.

As amostras foram preparadas no dia anterior à avaliação, mantidas sob refrigeração, a temperatura de $6 \pm 1^{\circ} \mathrm{C}$ e servidas, monadicamente, em copos plásticos de $50 \mathrm{~mL}$ em temperatura de geladeira. Os testes foram realizados em cabines individuais, no Laboratório de Análise Sensorial da EMBRAPA Agroindústria de Alimentos, sob iluminação branca, a fim de possibilitar a visualização da aparência dos produtos. Os consumidores utilizaram água mineral para lavar o palato entre uma amostra e outra.

\subsubsection{Análise estatística}

Os dados das determinações de composição química e rendimento dos leites foram analisados estatisticamente pelo modelo univariado tendo como principais causas de variação a temperatura, a extração e a interação dupla (temperatura $x$ extração). Testes de Tuckey foram usados para estudar diferenças entre médias.

Análises de correlações foram realizadas pelo teste de Spearman (não paramétrico), empregando-se estatística descritiva (histograma) para análise sensorial. 


\section{RESULTADOS E DISCUSSÃO}

\subsection{CASTANHA-DO-BRASIL}

Os resultados referentes à composição centesimal das castanhas-doBrasil com película e despeliculada estão apresentados na Tabela 1. Observou-se que os dados obtidos para as castanhas com película estão de acordo com MACRAE et al. (1993). Quanto à castanha despeliculada houve pequeno aumento nos teores de proteína, cinzas e óleo e decréscimo no teor de carboidratos devido à retirada da película rica em fibra.

\section{TABELA 1 - COMPOSIÇÃO CENTESIMAL (\%) DA CASTANHA-DO- BRASIL COM PELÍCULA E DESPELICULADA (BASE SECA)}

\begin{tabular}{lcccc}
\hline & \multicolumn{4}{c}{ Teor* $\left.^{*} \%\right)$} \\
\hline Tratamentos & Proteínas & Óleo & Carboidratos & Cinzas \\
\hline Com Película & 17,1 & 70,9 & 8,2 & 3,8 \\
Despeliculada & 17,9 & 74,9 & 3,3 & 3,9 \\
\hline
\end{tabular}

* Média de três determinações; ** Obtido por diferença.

\subsection{LEITES DE CASTANHA DO BRASIL DESPELICULADAS}

A Tabela 2 apresenta a composição centesimal dos leites de castanha despeliculada, obtida por diferentes variações nas temperaturas de extração e número de extrações.

Os resultados encontrados neste trabalho foram superiores para óleo e inferiores para matéria seca e proteínas comparativamente aos encontrados por REGITANO-d'ÁRCE e SIQUEIRA (1995). Tais autores utilizaram processamento em laboratório com diferentes condições, ou seja, leite de castanha elaborado a partir da torta semi-desengordurada na proporção de 1:2 (torta:água) com amido na formulação, que podem explicar a diferença entre os resultados. Em termos globais pode-se considerar que o processo em escala piloto utilizado neste trabalho foi mais vantajoso, pois empregando proporção 1:8 (castanha: água) foi obtida apenas metade do teor encontrado para matéria seca e proteínas pelos referidos autores. 


\section{TABELA 2 - COMPOSIÇÃO CENTESIMAL DOS LEITES DE CASTANHA DESPELICULADA OBTIDA POR DIFERENTES TRATAMENTOS}

\begin{tabular}{cc|cccc}
\hline \multicolumn{2}{c|}{$\begin{array}{c}\text { Condições de } \\
\text { Processamento }\end{array}$} & \multicolumn{4}{|c}{ Determinações $^{(1)}(\%)$} \\
\hline $\begin{array}{c}\text { Temperatura } \\
\left({ }^{\circ} \mathrm{C}\right)\end{array}$ & $\begin{array}{c}\text { Número } \\
\text { de } \\
\text { extrações }\end{array}$ & $\begin{array}{c}\text { Sólidos } \\
\text { Totais }\end{array}$ & Proteína & Óleo & Cinzas \\
\hline 25 & 1 & $8,5^{\mathrm{a}}$ & $1,5^{\mathrm{a}}$ & $6,2^{\mathrm{a}}$ & $0,3^{\mathrm{a}}$ \\
50 & 1 & $8,6^{\mathrm{a}}$ & $1,5^{\mathrm{a}}$ & $6,1^{\mathrm{a}}$ & $0,4^{\mathrm{b}}$ \\
75 & 1 & $9,7^{\mathrm{b}}$ & $1,7^{\mathrm{b}}$ & $7,1^{\mathrm{b}}$ & $0,4^{\mathrm{b}}$ \\
100 & 1 & $1,3^{\mathrm{c}}$ & $0,7^{\mathrm{c}}$ & $0,2^{\mathrm{c}}$ & $0,1^{\mathrm{c}}$ \\
\hline 25 & 2 & $8,6^{\mathrm{a}}$ & $1,5^{\mathrm{a}}$ & $6,3^{\mathrm{a}}$ & $0,2^{\mathrm{a}}$ \\
50 & 2 & $9,3^{\mathrm{b}}$ & $1,6^{\mathrm{bc}}$ & $6,7^{\mathrm{b}}$ & $0,2^{\mathrm{a}}$ \\
75 & 2 & $10,0^{\mathrm{c}}$ & $1,7^{\mathrm{c}}$ & $7,1^{\mathrm{c}}$ & $0,4^{\mathrm{b}}$ \\
100 & 2 & $9,2^{\mathrm{b}}$ & $1,6^{\mathrm{ab}}$ & $6,7^{\mathrm{b}}$ & $0,2^{\mathrm{a}}$ \\
\hline
\end{tabular}

${ }^{1}$ Letras iguais comparadas na mesma coluna entre temperaturas diferentes com o mesmo número de extrações indicam inexistência de diferença significativa ao nível de $5 \%$ pelo Teste de Tuckey.

O teor final de matéria seca verificado por SOUZA et al. (1987) foi maior que o ora relatado em função de maior concentração (proporção de 1:2, castanha: água). Neste trabalho, os leites que revelaram melhores resultados de extração apresentaram teor de sólidos em torno de 35\% mais baixo que o desses autores, mas com utilização de diluição 4 vezes maior. Os teores de cinzas e proteínas mostraram-se semelhantes, não havendo, portanto, desvantagem no rendimento de cinzas e proteínas. Deve-se ainda acrescentar que o teor de óleo no leite obtido pelo presente processo foi mais baixo, conferindo menos calorias ao produto. Desta forma, o processo aqui descrito foi considerado vantajoso em relação aos citados nos parâmetros estudados.

Ficou evidenciada interferência significativa $(p=0,05)$ da temperatura de extração, número de extrações e interação temperatura de extração $\mathrm{x}$ número de extrações no teor de sólidos e na composição química.

Observou-se que os leites elaborados a $75^{\circ} \mathrm{C}$ com uma e duas extrações resultaram em teores de sólidos significativamente superiores $(p=0,05)$ aos encontrados para os demais processamentos. Por outro lado, foi possível observar que, na temperatura de $100^{\circ} \mathrm{C}$ com uma extração, o teor de sólidos foi significativamente inferior aos demais processamentos. 
Este fato pode ser explicado devido à ocorrência de coagulação da proteína, com formação de compostos lipo-protéicos que ficaram retidos na centrífuga. Observou-se que a quantidade de resíduo foi superior aos demais experimentos, e que esse apresentou aparência visual gordurosa. Este fenômeno não se repetiu quando foram utilizadas duas extrações.

Os leites obtidos a $75^{\circ} \mathrm{C}$ com uma e duas extrações apresentaram teores de óleo, proteínas e cinzas, significativamente superiores $(p=0,05)$ aos demais processamentos, de forma semelhante ao ocorrido com os teores de sólidos totais. Os leites de castanha com uma extração e com duas extrações apresentaram, respectivamente, resultados de 9,7\% e 10,0\% para sólidos totais 1,7\% e 1,7\% para proteínas, 7,1\% e 7,1\% para teor de óleo e $0,4 \%$ e $0,4 \%$ para cinzas.

A Tabela 3 apresenta os resultados dos rendimentos do processo de obtenção dos leites de castanha em termos de sólidos totais, proteína e óleo. Os produtos extraídos a $75^{\circ} \mathrm{C}$ apresentaram rendimento em sólidos, proteína e óleo significativamente superior aos demais. Pode-se observar que a $100^{\circ} \mathrm{C}$ obteve-se o pior rendimento em termos de processo. Esses dados estão de acordo com a composição dos leites apresentados na Tabela 2 e discutidos anteriormente.

\section{TABELA 3 - RENDIMENTO (\%) DO PROCESSAMENTO, EM SÓLIDOS, PROTEÍNA E ÓLEO DOS LEITES DE CASTANHA DESPELICULADA OBTIDOS POR DIFERENTES TRATAMENTOS (VARIAÇÃO NA TEMPERATURA E NÚMERO DE EXTRAÇÕES)}

\begin{tabular}{cc|ccc}
\hline \multicolumn{2}{c|}{ Tratamentos } & \multicolumn{3}{c}{ Rendimentos (\%) } \\
\hline $\begin{array}{c}\text { Temperatura } \\
\left({ }^{\circ} \mathrm{C}\right)\end{array}$ & $\begin{array}{c}\text { Número de } \\
\text { extrações }\end{array}$ & $\begin{array}{c}\text { Em sólidos } \\
\text { totais }\end{array}$ & Em proteínas* & Em óleo* \\
\hline 25 & 1 & $65,0^{\mathrm{a}}$ & $65,5^{\mathrm{a}}$ & $67,2^{\mathrm{a}}$ \\
50 & 1 & $65,3^{\mathrm{a}}$ & $66,3^{\mathrm{a}}$ & $66,0^{\mathrm{a}}$ \\
75 & 1 & $71,3^{\mathrm{b}}$ & $72,3^{\mathrm{b}}$ & $73,7^{\mathrm{b}}$ \\
100 & 1 & $7,9^{\mathrm{c}}$ & $24,7^{\mathrm{c}}$ & $1,4^{\mathrm{c}}$ \\
\hline 25 & 2 & $64,2^{\mathrm{a}}$ & $67,3^{\mathrm{a}}$ & $66,8^{\mathrm{a}}$ \\
50 & 2 & $70,1^{\mathrm{b}}$ & $72,2^{\mathrm{b}}$ & $71,5^{\mathrm{b}}$ \\
75 & 2 & $74,4^{\mathrm{c}}$ & $73,8^{\mathrm{b}}$ & $75,1^{\mathrm{b}}$ \\
100 & 2 & $63,1^{\mathrm{a}}$ & $63,4^{\mathrm{c}}$ & $64,7^{\mathrm{a}}$ \\
\hline
\end{tabular}

* Letras iguais comparadas na mesma coluna entre temperaturas diferentes com o mesmo número de extrações indicam a inexistência de diferença significativa ao nível de $5 \%$ pelo teste de Tuckey. 
Embora o teor de sólidos e o rendimento em sólidos obtidos com duas extrações tenham sido significativamente superiores aos encontrados com apenas uma extração, tais diferenças ( $3 \%$ e $4,1 \%$ respectivamente) não foram consideradas relevantes para a escolha do processamento mais adequado para formulação. Desta forma, devido às vantagens de processo elegeu-se o leite elaborado a $75^{\circ} \mathrm{C}$ com uma extração, como o melhor processamento.

A Figura 1 apresenta o fluxograma do processamento de leite de castanhado-Brasil (Bertholletia excelsea) despeliculadas, com uma extração à $75^{\circ} \mathrm{C}$, selecionado para ser formulado e submetido à avaliação sensorial de doçura. O rendimento em sólidos totais, proteínas e óleo também pode ser observado nesta figura.

\subsection{AVALIAÇÃO SENSORIAL DE PREFERÊNCIA PARA DETERMINAÇÃO DA MELHOR CONCENTRAÇÃO DE SACAROSE}

O leite de castanha formulado segundo apresentado no item $2.2 .2 \mathrm{e}$ avaliado pelos consumidores alcançou as notas apresentadas na Tabela 4. Observou-se que os leites de castanha que alcançaram maior preferência quanto à doçura foram os formulados com $3 \%$ e $4 \%$ de açúcar, embora não tenham diferido significativamente $(p=0,05)$ entre si.

\section{TABELA 4 - ESTATÍSTICAS BÁSICAS DA PREFERÊNCIA QUANTO À DOÇURA DAS FORMULAÇÕES DE LEITE DE CASTANHA}

\begin{tabular}{rcc}
\hline Produto & \multicolumn{2}{c}{ Preferência quanto à doçura $^{1}$} \\
\hline & Média² $^{2}$ & Desvio padrão \\
Leite com 0\% de açúcar & $3,30^{\mathrm{a}}$ & 1,99 \\
Leite com 2\% de açúcar & $4,74^{\mathrm{b}}$ & 1,99 \\
Leite com 3\% de açúcar & $5,70^{\mathrm{c}}$ & 1,69 \\
Leite com 4\% de açúcar & $5,61^{\mathrm{c}}$ & 2,01 \\
\hline
\end{tabular}

${ }^{1}$ Escala de 9 pontos;

2 Letras diferentes implicam em diferença estatisticamente significativa ao nível de 5\%. 


\section{FIGURA 1 - FLUXOGRAMA DO PROCESSO DE OBTENÇÃO DE LEITE DE CASTANHA-DO-BRASIL DESPELICULADA A $75^{\circ} \mathrm{C}$ E UMA EXTRAÇÃO}

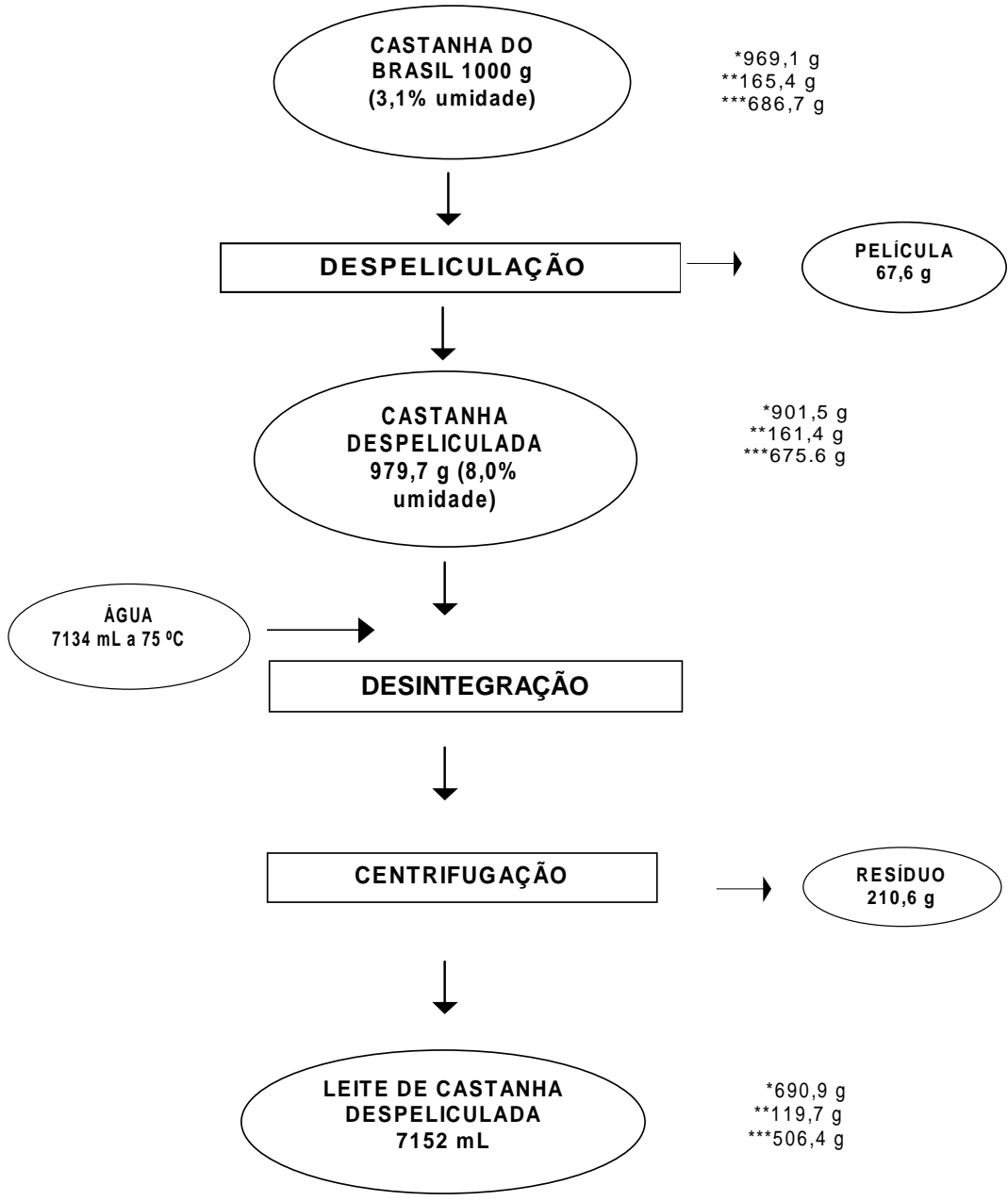

RENDIMENTO

Sólidos Totais ... 71,3\%

Proteínas .......... 72,3\%

Lipídios ............. 73,7\%

* Sólidos Totais; ** Proteínas; ${ }^{* * *}$ Lipídios. 
Observando-se as notas individuais dos consumidores foi possível verificar que alguns gostaram bastante dos produtos. Construindo histogramas de freqüência (Figura 2) para a preferência para cada produto verificou-se que o leite de castanha com $3 \%$ de açúcar alcançou maior freqüência de notas 6, 7 e 8, assim como menor rejeição (menor freqüência de notas 1 e 2) dentre os 4 tratamentos estudados. A partir dos dados da Figura 2 sugere-se a adição de 3\% de açúcar como adequada na formulação de leite de castanha.

\section{FIGURA 2 - HISTOGRAMA DE PREFERÊNCIA DE DOÇURA DOS QUATRO LEITES DE CASTANHA-DO-BRASIL AVALIADOS}
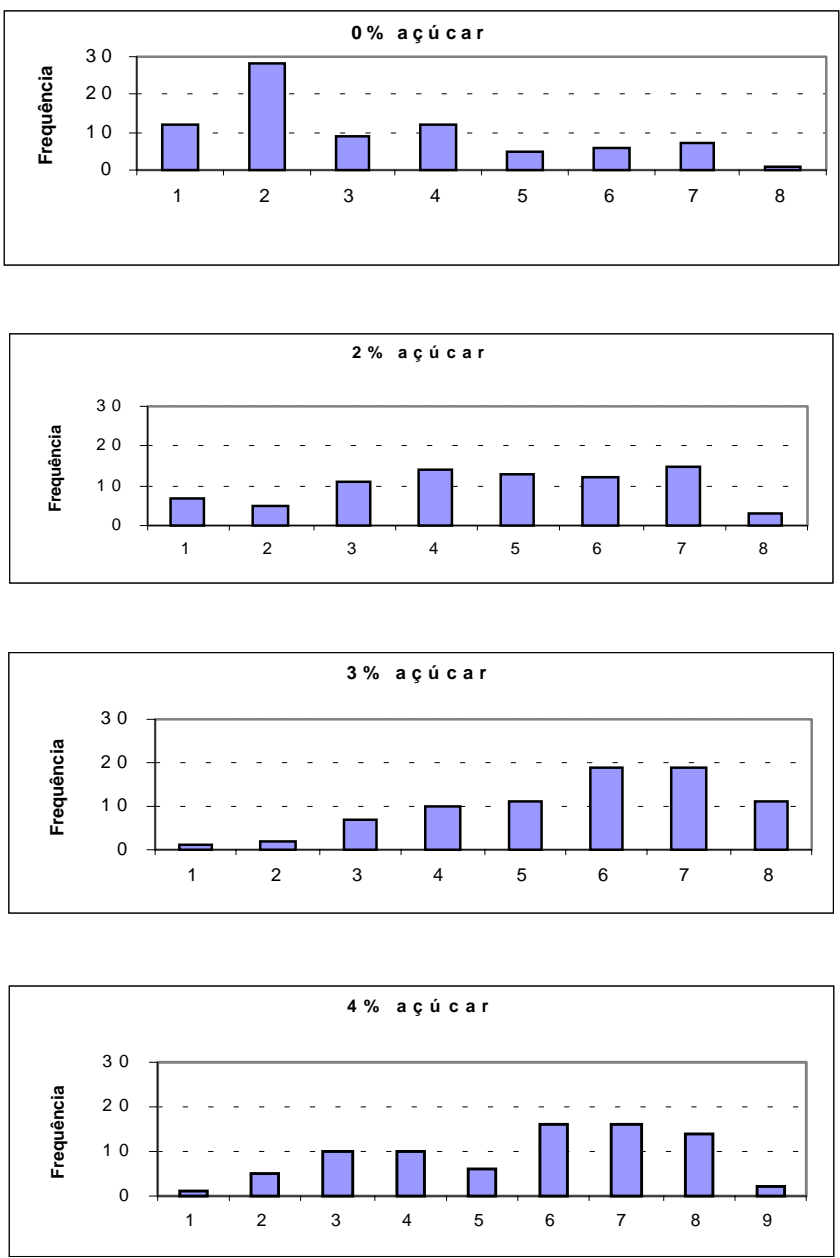


\title{
4 CONCLUSÃO
}

A composição, os sólidos e os rendimentos dos leites de castanha variaram conforme a temperatura e número de extrações. Os melhores rendimentos em extração foram obtidos na temperatura de $75^{\circ} \mathrm{C}$.

Possivelmente devido à coagulação de proteína e separação do óleo ocorreu queda brusca de rendimento em sólidos no leite elaborado a $100^{\circ} \mathrm{C}$ com uma extração.

Os consumidores preferiram os leites com 3 e 4\% de adição de açúcar. Entretanto a adição de 3\% foi considerada a melhor por apresentar as mais baixas freqüências de rejeição.

\begin{abstract}
EFFECT OF EXTRACTION CONDITIONS IN YIELD AND QUALITY OF SKINNED BRAZILIAN NUTS MILK

The objective of the present work was to evaluate the extraction conditions in yield and quality of skinned brazilian nuts milk. The basic process for the elaboration of such milk included the stages of skinning the brazilian nuts, desintegration of the skinned nuts and centrifugation of the product. In the stage of desintegration 4 temperatures were studied $\left(25,50,75\right.$, and $\left.100^{\circ} \mathrm{C}\right)$ with one or two extractions. The experimental samples obtained were evaluated for composition, extraction yield and sensorial evaluation of sweetness. The nut milks obtained at $75^{\circ} \mathrm{C}$ with 1 or 2 extractions presented solid yield, proteins and oil significantly superior to the others. The nut milk elaborated at $75^{\circ} \mathrm{C}$ with one extraction considered the best in the technological point of view, was formulated with different concentrations of sugar (2, 3 e $4 \%$ ) and submitted to preference test. The nut milk with $3 \%$ of sugar was prefered by $78 \%$ of consumers that evaluated the product.
\end{abstract}

KEY WORDS: BRAZILIAN NUTS - EXTRACTION ; BRAZILIAN NUTS-YIELD.

\section{REFERÊNCIAS}

1 ANTONIASSI, R.; ROBBS, C.F.; SILVA, O.F.; FARIAS, A.X. Problemas decorrentes do processamento de castanha-do-Brasil. In: CONGRESSO BRASILEIRO DE CIÊNCIA E TECNOLOGIA DE ALIMENTOS, 16., 1998, Rio de Janeiro. Anais... Rio de Janeiro: SBCTA, 1998. p.1943-1946.

2 ANTUNES, A. J.; MARKAKIS, P. Proteins supplementation of navy beans with Brazil nuts. Journal Agriculture and Food Chemistry, Washington, v.25, n.5, p.1096-1097, 1977. 
3 AOCS. American Oil Chemists' Society. Official methods and recommended practices of the American Oil Chemists' Society. Champaign, IL., 1997.

4 AOAC. Association of Official Analytical Chemists. Official methods of analysis of the Association of Official Analytical Chemists. Washington, 1996.

5 BLIGH, E.G.; DYER, W.J. A rapid method of total lipid extraction and purification. Canadian Journal of Biochemistry and Phisiology, v. 37, n.8, p.911-917, 1959.

6 BONELLI, P.R.; DELLA ROCCA, P.A.; CERRELLA, E.G.; CUKIERMAN, A.L. Effect of pyrolysis temperature on composition, surface properties and thermal degradation rates of Brazil nuts shells. Bioresource Technology, v.76, n.1, p.15-22, 2001.

7 CARDARELLI, H.R.; OLIVEIRA, A. J.; REGITANO-d'ARCE, M.A.B. Controle microbiológico de extrato fluído de castanha-do-Pará (Bertholletia excelsa). In: CONGRESSO BRASILEIRO DE MICROBIOLOGIA, 17., Santos, 1995. Resumos... Santos: SBM, 1995. p.211.

8 CASTANHA: produtos potenciais da Amazônia. Brasília: MMA/ SUFRAMA/SEBRAE/ GTA, 1998. $88 \mathrm{p}$.

9 LEAVANDER, O.A. Recent developments in selenium nutrition. In: WEININGER J., BRIGGS, G. M. (Eds). Nutrition update. [New York]: Wiley-Interscience, 1983. v.1, p.147- 162.

10 MacFIE, H.J.H.; BRATCHELL, N.; GREENHOFF, K.; VALLIS, L.V. Designs to balance the effect of order of presentation and first-order carry-over effects in hall tests. J. Sensory Studies, Connecticut, v. 4, p. 129-148, 1989.

11 MACRAE, R.; ROBINSON, R. K.; DADLER, M. Brazil nuts. In: MACRAE, R.; ROBINSON, R. K.; DADLER, M. (Eds). Encyclopaedia of food science food technology and nutrition. London: Academic Press, 1993. v.1, p.458-461.

12 PEREIRA, P.L. Extratos solúveis da castanha-do-Brasil (Bertholletia excelsa, H.B.K.) 1976. 43 f. Dissertação (Mestrado 
em Ciência e Tecnologia de Alimentos) - Faculdade de Engenharia de Alimentos e Agrícola, Universidade Estadual de Campinas, Campinas.

13 REGITANO-d'ARCE, M.A.B.; SIQUEIRA F. M. Obtenção do leite e farinhas de castanha do Pará (Bertholettia excelsa). In: CONGRESSO E EXPOSIÇÃO LATINO-AMERICANO SOBRE PROCESSAMENTO DE ÓlEOS E GORDURAS, 6., Campinas, 1995. Anais... Campinas: Sociedade Brasileira de Óleos e Gorduras, 1995. p. 265-267.

14 RIBEIRO,M.A.A; SOLER,R.M.; REGITANO-d'ARCE, M.A.B.; LIMA, V.A. Shelled Brazil nuts canned under different atmospheres. Ciência e Tecnologia de Alimentos, Campinas, v.15, n.2, p.105-107, jul./ dez. 1995.

15 SANT'ANNA, N.M.G. Desenvolvimento e estudo de estabilidade e embalagem de alimentos formulados contendo castanha-doPará. Viçosa, 1985. 80 f. Dissertação (Mestrado em Ciência e Tecnologia de Alimentos) - Universidade Federal de Viçosa, MG.

16 SIGHTINGS. New link between nutrition and no melanoma skin cancers. Disponível em: <http://www.sciencedaily.com>. Acesso em 03.03.98.

17 SOUZA, M.L. de; HOLANDA, L.F.F. de; MAIA, G.A.; JUNIOR, J.C.G.; FIGUEIREDO, R.W. de. Processamento e estabilidade do leite de amêndoa de castanha-do-Brasil (Bertholletia excelsa H.B.K.). Ciência Agronômica, Fortaleza, v. 18, n.1, p.137-146, jun.1987.

18 SUN, S.S.M.; LEUNG, F.W.; TOMIC, J.C. Brasil nut (Bertholetia excelsa H.B.K.) proteins: fractionation, composition and indentification of a sulfur-rich protein. Journal Agricultural and Food Chemistry, Washington, v.35, p.232-235, 1987.

19 WOODROOF, J.G. Tree nuts: production, processing, products. $2^{\text {nd }}$ ed. Westport: AVI Publishing, 1982. $731 \mathrm{p}$.

20 VIEIRA, T.M.F.S.; REGITANO-d'ARCE, M.A.B. Antioxidant concentration effect on stability of Brazil nut (Bertholletia excelsa) crude oil. Archivos Latino Americanos de Nutricion, Guatemala, v.49, n.3, p.271-274, 1999. 